\title{
COMPLICAÇÕES ASSOCIADAS AO PREENCHIMENTO FACIAL COM ÁCIDO HIALURÔNICO: uma revisão da literatura
}

DOI: 10.22289/2446-922X.V7N2A18

\author{
Anne Karoline Custódio Teixeira \\ Nára Gabriela do Nascimento Niza \\ Noelhia dos Santos Gonçalves \\ Thamires Santos Silva \\ Gabriel Nunes Pereira Reis \\ Marcone de Oliveira Rocha ${ }^{1}$
}

\section{RESUMO}

Objetivo: Revisar a literatura sobre as complicações associadas ao preenchimento facial com ácido hialurônico. Materiais e Métodos: Este estudo constituiu de uma revisão bibliográfica da literatura pautada em bases de dados nacionais e internacionais como: PubMed e SciELO. Resultados e Discussão: Foram selecionados 14 estudos, onde pode ser observada a existência de várias complicações relacionadas com o uso do ácido hialurônico, podem ocorrer efeitos colaterais precoces, que são aqueles que aparecem logo após aplicação e persistem em torno de 15 dias e também podem ocorrer efeitos colaterais tardios. Conclusões: Apesar de toda segurança da técnica de preenchimento com ácido hialurônico é possível ocorrer complicações, sendo necessário o profissional está apto a intervir nestas situações.

Palavras-chave: Ácido Hialurônico; Preenchedores Dérmicos; Necrose.

\section{COMPLICATIONS ASSOCIATED WITH FACIAL FILLING WITH HYALURONIC ACID: a literature review}

\begin{abstract}
Objective: To review the literature on complications associated with facial filling with hyaluronic acid. Materials and Methods: This study consisted of a literature review based on national and international databases such as: PubMed and SciELO. Results and Discussion: 14 studies were selected, where the existence of several complications related to the use of hyaluronic acid can be observed, early side effects can occur, which are those that appear soon after application and persist for around 15 days and can also late side effects occur. Conclusions: Despite all the safety of the filling technique with hyaluronic acid, complications can occur, requiring the professional to be able to intervene in these situations.
\end{abstract}

Keywords: Hyaluronic Acid; Dermal Fillers; Necrosis.

\footnotetext{
${ }^{1}$ Endereço eletrônico de contato: marconeoliveirarocha@yahoo.com.br

Recebido em 31/07/2021. Aprovado pelo conselho editorial para publicação em 22/10/2021.
}

Rev. Psicol Saúde e Debate. Out., 2021:7(2): 286-294. 


\section{COMPLICACIONES ASOCIADAS CON EL RELLENO FACIAL CON ÁCIDO HIALURÓNICO: una revisión de la literatura}

\section{RESUMEN}

Objetivo: Revisar la literatura sobre las complicaciones asociadas al relleno facial con ácido hialurónico. Materiales y Métodos: Este estudio consistió en una revisión de la literatura basada en bases de datos nacionales e internacionales como: PubMed y SciELO. Resultados y Discusión: Se seleccionaron 14 estudios, donde se puede observar la existencia de varias complicaciones relacionadas con el uso de ácido hialurónico, pueden presentarse efectos secundarios tempranos, que son los que aparecen poco después de la aplicación y persisten alrededor de 15 días y también pueden aparecer tardíamente. ocurren efectos secundarios. Conclusiones: A pesar de toda la seguridad de la técnica de llenado con ácido hialurónico, pueden presentarse complicaciones que obliguen al profesional a poder intervenir en estas situaciones.

Palabras clave: Ácido Hialurónico; Rellenos Dérmicos; Necrosis.

\section{INTRODUÇÃO}

O envelhecimento ocorre através de uma somatória de fatores intrínsecos (maturação de partes moles, atrofia muscular e mudanças esqueléticas) e extrínsecos (gravidade e dano solar) que se correlacionam. É comum o esqueleto de modo geral diminuir na altura e aumentar sutilmente sua largura. No processo fisiológico a camada epidérmica diminui sua espessura enquanto a derme reduz sua elasticidade, a perda de volume é caracterizada pela diminuição ou realocação do tecido adiposo facial (Bispo, 2019; Crocco et al., 2012; Daher et al., 2020; Faria \& Júnior, 2020).

O preenchimento facial é um procedimento estético injetável não cirúrgico utilizado para tratar sulcos, rugas, corrigir cicatrizes atróficas e melhorar o contorno facial. O ácido hialurônico é o produto mais utilizado por oferecer praticidade de aplicação, boa margem de segurança e considerável biocompatibilidade (Daher, Da-Silva, Campos, Dias, Damasio, \& Costa, 2020; Coalhado et al., 2009; Faria \& Junior, 2020; Gutmann \& Dutra, 2018).

O ácido hialurônico é uma molécula já presente no organismo, responsável por atrair e reter a água ao seu redor, dando mais viço, firmeza e textura homogênea à pele e tem algumas particularidades que o diferenciam de alguns preenchedores, como o tamanho da partícula, mais viscoelasticidade, diferença no comprimento de cadeia dos polímeros, e tipo e densidade de crosslinker, com o objetivo de obter o melhor resultado na acomodação do produto na pele, sem risco de migração do local da injeção. Sua aplicação é feita nos planos supraperiostal ou subcutâneo profundo, podendo ser utilizadas cânulas, que reduzem o risco de sangramento (Daher, Da-Silva, Campos, Dias, Damasio, \& Costa, 2020; Faria \& Júnior, 2020; Gutmann \& Dutra, 2018).

Os preenchimentos faciais tem um perfil de segurança muito favorável, mas não há existência de preenchedores totalmente desprovido de riscos e mesmo profissionais experientes podem se deparar com reações imediatas(Daher, Da-Silva, Campos, Dias, Damasio, \& Costa, 2020;

Rev. Psicol Saúde e Debate. Out., 2021:7(2): 286-294. 
Faria \& Júnior, 2020; Gutmann \& Dutra, 2018). Diante disso, o objetivo deste trabalho foi revisar a literatura sobre as complicações associadas ao preenchimento facial com ácido hialurônico.

\section{MATERIAIS E MÉTODOS}

Este estudo constituiu de uma revisão bibliográfica da literatura, acerca das complicações associadas ao preenchimento facial com ácido hialurônico, pautada em artigos indexados em bases de dados nacionais e internacionais como: PubMed e SciELO. Foram buscados artigos completos, sendo estes avaliados obedecendo aos critérios de inclusão e exclusão dos estudos. As palavraschaves utilizadas foram: "Preenchimento facial" and "Complicações" and "Ácido Hialurônico".

Foram incluídos os estudos com textos completos em suporte eletrônico, estudos que atendiam a proposta do presente estudo, apresentados em idioma inglês e português. Além disso, foram excluídos resumos publicados em anais de congressos, pesquisas que não atendiam ao tema proposto e estudos antigos.

A busca dos estudos foi realizada entre os meses de março e abril de 2021 e a seleção foi feita a partir da leitura dos resumos previamente selecionados. Foi feita a leitura completa de estudos que atendiam ao tema proposto. Foram excluídos os estudos que não se encaixaram nos critérios de inclusão supracitados.

Após busca pelas palavras-chaves e leitura dos resumos dos artigos encontrados, 22 artigos foram selecionados para leitura na íntegra, dos quais 08 foram excluídos (Figura 1). Sendo analisados 14 estudos científicos que foram submetidos à etapa de classificação e caracterização da sua metodologia e incluídos em caráter final na revisão. 
Figura 1. Fluxograma de resultados de busca

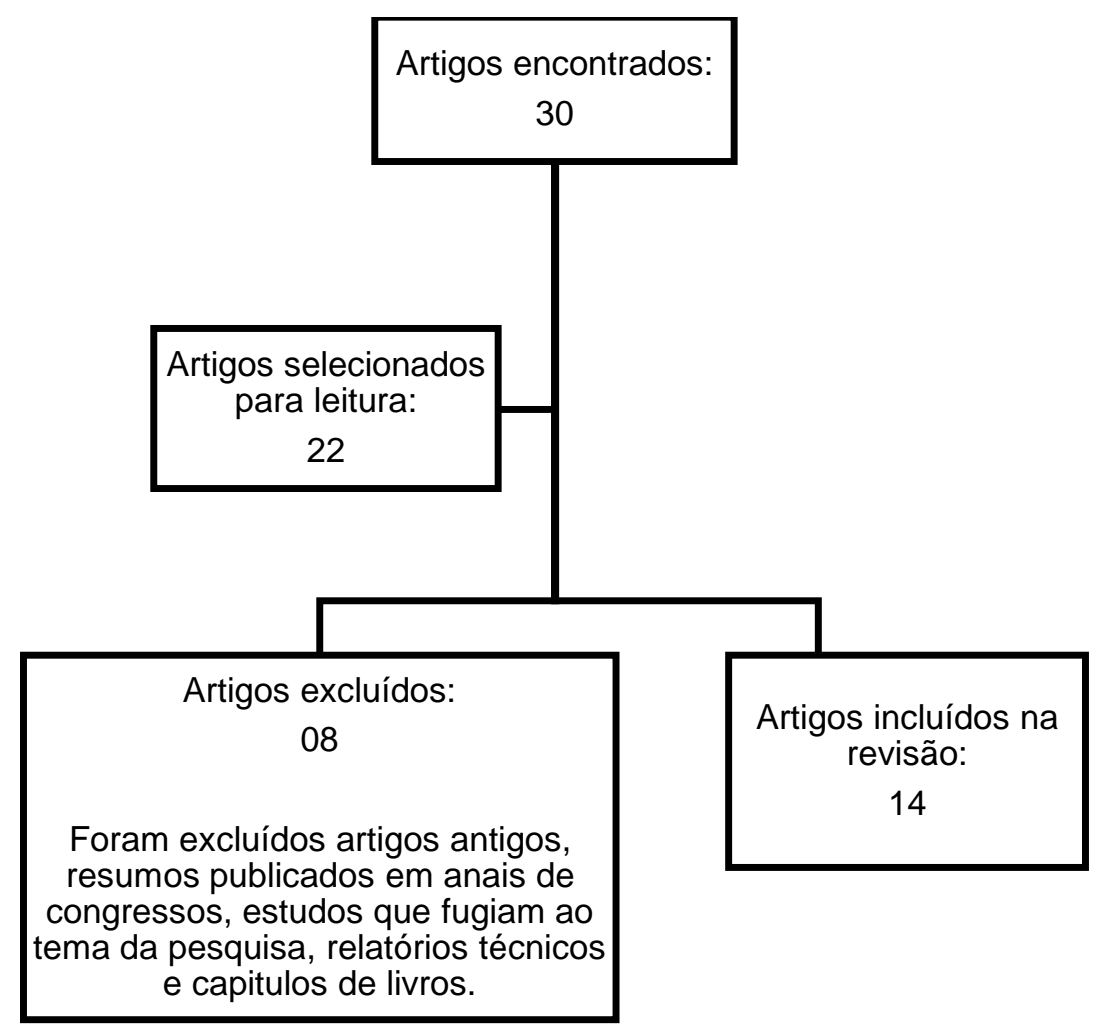

Fonte: Elaborado pelos pesquisadores.

\section{RESULTADOS E DISCUSSÃO}

Após análise dos 14 estudos, pode ser observada a existência de várias complicações relacionadas com o uso do ácido hialurônico, onde podem ocorrer efeitos colaterais precoces, que são aqueles que aparecem logo após aplicação e persistem em torno de 15 dias, onde ocorrem reações inflamatórias, hematomas, necrose tecidual e edema persistente e também podem ocorrer efeitos colaterais tardios, como: granulomas, biofilmes e migração tecidual (Bispo, 2019; Crocco et al., 2012; Coalhado et al., 2009; Faria \& Júnior, 2020; Ferreira \& Capobiano, 2016; Maia \& Salvi, 2018; Vasconcelos et al., 2020). 
Quadro 1. Principais complicações da aplicação do Ácido Hialurônico

\begin{tabular}{|c|c|c|}
\hline \multicolumn{3}{|c|}{ Efeitos Colaterais Precoces } \\
\hline Complicação & O que pode ter causado? & Manejo \\
\hline Hematoma & $\begin{array}{l}\text { A injeção inadvertida dos } \\
\text { vasos sanguíneos ou a } \\
\text { compressão e ruptura } \\
\text { secundária dos vasos. } \\
\text { Quanto mais profundo for o } \\
\text { vaso, maior o risco de } \\
\text { sangramento volumoso } \\
\text { (Gutmann \& Dutra, 2018). }\end{array}$ & $\begin{array}{l}\text { Pode ser tratada com injeção } \\
\text { local de hialuronidase (Faria \& } \\
\text { Júnior, 2020). }\end{array}$ \\
\hline Reações Alérgicas & $\begin{array}{l}\text { Ocorre de } 3 \text { a } 7 \text { dias após a } \\
\text { aplicação, mas também } \\
\text { pode se estender até o } \\
\text { período de } 1 \text { a } 6 \text { meses. } \\
\text { Podendo ocorrer com } \\
\text { qualquer material de } \\
\text { preenchimento (Gutmann \& } \\
\text { Dutra, 2018). }\end{array}$ & $\begin{array}{l}\text { Uso de anti-histamínicos, } \\
\text { corticoide oral ou infiltração } \\
\text { intralesional de corticoide } \\
\text { (Gutmann \& Dutra, 2018). }\end{array}$ \\
\hline Eritema e Edema & $\begin{array}{l}\text { Múltiplas injeções, material } \\
\text { espesso e técnica incorreta } \\
\text { de aplicação (Gutmann \& } \\
\text { Dutra, 2018). }\end{array}$ & $\begin{array}{l}\text { Anti-histamínicos e esteroides } \\
\text { tópicos podem ajudar a } \\
\text { amenizar a vermelhidão } \\
\text { transitória. Já para o edema, a } \\
\text { aplicação de gelo, a elevação } \\
\text { da cabeça e prednisona orais } \\
\text { por curto espaço (Gutmann \& } \\
\text { Dutra, 2018). }\end{array}$ \\
\hline $\begin{array}{l}\text { Efeito "Tyndall" - } \\
\text { Coloração azulada no local } \\
\text { da aplicação. }\end{array}$ & $\begin{array}{l}\text { Ocorre quando o } \\
\text { preenchedor é aplicado } \\
\text { superficialmente e devido à } \\
\text { transparência da pele fina, } \\
\text { verifica-se uma cor } \\
\text { azulada, que é resultante } \\
\text { de vestígios de } \\
\text { hemossiderina após lesão }\end{array}$ & \begin{tabular}{llr} 
Massagem local, incisão, & \multicolumn{2}{r}{ da } \\
drenagem e uso d \\
hialuronidase \\
Dutra, 2018).
\end{tabular} \\
\hline
\end{tabular}




\begin{tabular}{|c|c|c|}
\hline & $\begin{array}{l}\text { vascular ou distorção visual } \\
\text { de refração da luz através } \\
\text { da pele causada pelo } \\
\text { material de preenchimento } \\
\text { (Gutmann \& Dutra, 2018). }\end{array}$ & \\
\hline Infecção & $\begin{array}{l}\text { Contaminação do produto } \\
\text { ou técnica inadequada de } \\
\text { assepsia do paciente, } \\
\text { podendo ser de origem } \\
\text { bacteriana ou viral } \\
\text { (Gutmann \& Dutra, 2018). }\end{array}$ & $\begin{array}{l}\text { O tratamento é o antibiótico } \\
\text { adequado à cultura e } \\
\text { drenagem de abcessos quando } \\
\text { necessário (Gutmann \& Dutra, } \\
\text { 2018). }\end{array}$ \\
\hline Nódulos & $\begin{array}{l}\text { Resultante de um erro } \\
\text { técnico de posicionamento } \\
\text { do produto, como injeção } \\
\text { do material de } \\
\text { preenchimento muito } \\
\text { superficial (Faria \& Júnior, } \\
\text { 2020; Gutmann \& Dutra, } \\
\text { 2018). }\end{array}$ & $\begin{array}{l}\text { Aplicação de hialuronidase } \\
\text { (Faria \& Júnior, 2020; Gutmann } \\
\text { \& Dutra, 2018). }\end{array}$ \\
\hline Necrose tecidual & $\begin{array}{l}\text { Pode ocorrer pela oclusão } \\
\text { vascular através da injeção } \\
\text { no vaso com a substância } \\
\text { preenchedora ou do } \\
\text { aumento de pressão } \\
\text { externa exercido pelo } \\
\text { volume da substância } \\
\text { preenchedora, paralisando } \\
\text { o fluxo sanguíneo (Faria \& } \\
\text { Júnior, 2020; Gutmann \& } \\
\text { Dutra, 2018). }\end{array}$ & $\begin{array}{l}\text { Massagem e usar compressas } \\
\text { mornas no local, utilizar pasta } \\
\text { de nitroglicerina a } 2 \% \text { e fazer } \\
\text { nas primeiras } 24 \text { horas a } \\
\text { injeção de hialuronidase (Faria } \\
\text { \& Júnior, 2020; Sales et al., } \\
\text { 2011). }\end{array}$ \\
\hline \multicolumn{3}{|c|}{ Efeitos Colaterais Tardias } \\
\hline Complicação & O que pode ter causado? & Manejo \\
\hline Granulomas & $\begin{array}{l}\text { Pode ocorrer pela presença } \\
\text { de impurezas no processo } \\
\text { de fermentação bacteriana } \\
\text { na produção de ácido }\end{array}$ & $\begin{array}{l}\text { Aplicação de hialuronidase ou } \\
\text { infiltração intralesional de } \\
\text { corticoide (Faria \& Júnior, } \\
\text { 2020; Gutmann \& Dutra, 2018). }\end{array}$ \\
\hline
\end{tabular}




\begin{tabular}{|c|c|c|}
\hline & $\begin{array}{l}\text { hialurônico, exposição à luz } \\
\text { solar excessiva e uso de } \\
\text { drogas sistêmicas } \\
\text { (Gutmann \& Dutra, 2018). }\end{array}$ & \\
\hline Biofilmes & $\begin{array}{l}\text { São formados por bactérias } \\
\text { ou microrganismos } \\
\text { infecciosos que } \\
\text { contaminem a injeção. O } \\
\text { biofilme pode permanecer } \\
\text { em estado latente até ser } \\
\text { ativado por trauma local, } \\
\text { manipulação e injeções } \\
\text { (Gutmann \& Dutra, 2018). }\end{array}$ & $\begin{array}{l}\text { Para o tratamento, é } \\
\text { recomendado o uso de dois } \\
\text { antibióticos de largo espectro } \\
\text { (Gutmann \& Dutra, 2018). }\end{array}$ \\
\hline Migração do material & $\begin{array}{l}\text { Pode ocorrer devido à má } \\
\text { técnica, alto volume } \\
\text { injetado, realização da } \\
\text { injeção sob pressão, } \\
\text { massageamento } \\
\text { inadequado, atividade } \\
\text { muscular ou deslocamento } \\
\text { induzido por excessivas } \\
\text { pressões (Gutmann \& } \\
\text { Dutra, 2018). }\end{array}$ & $\begin{array}{l}\text { Pode ser tratada com injeção } \\
\text { local de hialuronidase (Parada, } \\
\text { 2016). }\end{array}$ \\
\hline
\end{tabular}

Fonte: Elaborado pelos pesquisadores

Atualmente observa-se o aumento pela procura por procedimentos estéticos não cirúrgicos, com objetivo de melhorar a aparência, rejuvenescer e ter uma melhor harmonia da face. A técnica de preenchimento facial com ácido hialurônico é considerada segura, mas é possível ocorrer complicações.

Em algumas destas complicações é utilizado a hialuronidase que age despolimerizando reversivelmente o ácido hialurônico existente ao redor das células do tecido conjuntivo, reduzindo assim temporariamente a viscosidade desse tecido e tornando-o mais permeável à difusão de líquidos. Deve-se atentar para evitar hidrólise excessiva desse ácido podendo resultar no rosto do paciente um aspecto atrófico e depressivo (Gutmann \& Dutra, 2018). É essencial o profissional ter 
conhecimento do manejo destas complicações para oferecer ao paciente um tratamento seguro e eficaz.

Algumas complicações podem ocorrer devido a reações alérgicas de pacientes às substâncias químicas presentes no material que é utilizado nas aplicações e também aos componentes proteicos que estão presentes nas preparações (Ferreira \& Capobiano, 2016; Vasconcelos et al., 2020). Sendo necessário realizar uma anamnese detalhada a fim de evitar qualquer complicação por conta de uma reação alérgica.

As reações alérgicas ao material ou por resposta imunológica aos componentes acontecem de três a sete dias após a aplicação, podendo se estender de um ano a seis meses, que são os efeitos colaterais tardios (Bispo, 2019; Vasconcelos et al., 2020).

Recomendações importantes para prevenir reações adversas na aplicação preenchedores: Aspirar antes de injetar o produto para verificar se a agulha não está em uma artéria ou veia, optar por uso de microcânulas com ponta romba e usar delicadeza, aplicar pequenos volumes por vez, diminuir o tamanho do êmbolo e prevenir altas pressões no local e não associar outros procedimentos junto ao preenchimento (Bispo, 2019; Castro et al., 2007; Parada et al., 2016; Sales et al., 2011; Shoughy, 2019; Tavares et al., 2017; Vasconcelos et al., 2020). Sendo fundamental o conhecimento detalhado da anatomia facial, para minimizar os riscos de injeção intravenosa ou intravascular, com intuito de prevenir complicações vasculares.

\section{CONSIDERAÇÕES FINAIS}

Apesar de toda segurança da técnica de preenchimento com ácido hialurônico é possível ocorrer complicações, sendo necessário o profissional está apto a intervir nestas situações. O ideal é evitar intercorrências, para isso é fundamental conhecimento técnico e de anatomia.

\section{REFERÊNCIAS}

Bispo L. B. (2019). A bichectomia na harmonização e função orofacial. Rev. Odontol. Univ. Cid, São Paulo, set-dez; 31(3):82-90.

Castro A. C. B., Collares M. V. M., Portinho P. C. D, Dias P. C., Pinto R. A. (2007). Necrose facial extensa após infiltração com polimetilmetacrilato. Revista brasileira de otorrinolaringologia, novdez; 73(6).

Coalhado O. C. G., Boeing M., Ortega L. B. (2009). Toxina Botulínica no Tratamento da Dor. Revista Brasileira de Anestesiologia. mai-jun; 59(3).

Crocco, E. I., Alves, R. O., Alessi, C. (2012). Adverse Events in Injectable Hyaluronic Acid. Surg Cosmet Dermatol, 4(3):259-63. 
Daher J. C., Da-Silva S. V., Campos A. C., Dias R. C. S., Damasio A. A., Costa R. S. C. (2020). Complicações vasculares dos preenchimentos faciais com ácido hialurônico: confecção de protocolo de prevenção e tratamento. Rev. Bras. Cir. Plást, 35(1): 3.

Faria T. R., Júnior J. B. (2020). Possíveis intercorrências do preenchimento facial com ácido hialurônico. Revista Conexão Ciência Formiga, 15(3):71-72.

Ferreira N. R., Capobiano M. P. (2016). Uso do ácido hialurônico na prevenção do envelhecimento facial. Revista Cientifica UNILAGO, 1(1).

Gutmann E. I., Dutra R. T. (2018). Reações adversas associados ao uso de preenchimento faciais com ácido hialurônico. Revista eletrônica biociências, biotecnologia e saúde, mai-ago; 11(20).

Maia I. E. F., Salvi J. O (2018). O uso do ácido hialurônico na harmonização facial: uma breve revisão. Brazilian Journal of Surgery and Clinical Research, jun/ago; 23(2):135- 137.

Parada M. B., Cazerta C., Afonso J. P. J. M., Nascimento D. I. S. (2016). Manejo de complicações de preenchedores dérmicos. Surgical\&Cosmetic Dermatology, 8(4):342-351.

Salles A. G, Remígio., A. F. N., Saito O. C, Camargo C.P., Zacchi V.B.L., Saito P. L., Ferreira M. C. (2011). Avaliação clínica de espessura cutânea um ano após preenchimento de ácido hialurônico. Revista brasileira de cirurgia plástica, São Paulo; 26(1): 66-9.

Shoughy S. S. (2019). Perda visual após injeção cosmética de preenchimento facial. Arq Bras Oftalmol, 82(6):511-512.

Tavares J. P., Oliveira C. A. C. P, Torres R. P., Júnior F. B (2017). Rejuvenescimento facial com fios de sustentação, Braz. j. otorhinolaryngol. São Paulo 2017; 83(6).

Vasconcelos, S. C. B., Nascente, F. M., Souza, C. M. D., Rocha Sobrinho, H. M. (2020). O uso do ácido hialurônico no rejuvenescimento facial. revista brasileira militar de ciências, 6(14). https://doi.org/10.36414/rbmc.v6i14.28. 